\title{
Female Sexual Dysfunction Among the Wives of Opioid-Dependent Males in Iran
}

\author{
Marjan Anvar Abnavi, Jamshid Ahmadi, ${ }^{2}$ Sajedeh Hamidian,, ${ }^{3, *}$ and Sara Ghaffarpour ${ }^{4}$ \\ ${ }^{1}$ Substance Abuse Research Center and Psychiatry Research Center, Shiraz University of Medical Sciences, Shiraz, IR Iran \\ ${ }^{2}$ Substance Abuse Research Center, Shiraz University of Medical Sciences, Shiraz, IR Iran \\ 3 Department of Psychiatry, Shiraz University of Medical Sciences, Shiraz, IR Iran \\ ${ }^{4}$ Faculty of Medicine, Shiraz University of Medical Sciences, Shiraz, IR Iran \\ ${ }^{*}$ Corresponding author: Sajedeh Hamidian. Department of Psychiatry, Shiraz University of Medical Sciences, Shiraz , IR Iran. Tel: +98-9173915289, Fax: +98-21180045, E-mail: Sajedeh. \\ hamidian@gmail.com
}

Received 2014 November 19; Revised 2015 March 10; Accepted 2015 April 26.

\begin{abstract}
Background: Opiate abuse in males has significant effects on their sexual functions. In contrast, sexuality in females is a multidimensional issue that can strongly be affected by several factors in their partners. However, only a limited number of studies have assessed the role of males' opioid dependency in their female partners' sexual function.

Objectives: The present study aimed to evaluate the effect of males' opioid dependency on their wives' sexual function compared to the sexual function of the females whose husbands were not opioid dependent.

Patients and Methods: This study included 340 women who were selected through convenience sampling and divided into a control (females whose husbands were not opioid dependent) and a case group (women whose husbands were opioid dependent). The data were collected through an interview according to the DSM-IV-R criteria for female sexual dysfunctions by a senior female medical student who was one of the researchers. Finally, the data were entered into the SPSS statistical software (v.15) and analyzed using the t-test and chi-square test.

Results: According to the results, the frequency of hypoactive sexual desire disorder and sexual aversion disorder in the control group was significantly higher than that of the case group $(\mathrm{P}<0.05)$.

Conclusions: The results showed that having an addicted husband could strongly affect some sexual domains in women. It could change the pattern of desire and motivation for sexual contact in females and alter their attitude toward the sexual relationship, thereby causing disturbances in the females' normal sexual function.
\end{abstract}

Keywords: Sexual Dysfunctions, Psychological, Aversion Disorders, Sexual-Opioid-Related Disorders

\section{Background}

Sexuality in women is a complex issue with physiological, psychological, and cultural components. Determination of sexual partner involvement, intimate relationships, and past abusive relationships is crucial in female sexual dysfunction (FSD) $(1,2)$. Sexual dysfunction is more prevalent among women compared to men (43\% vs. $31 \%$ ) (3-5). In 1960, Masters and Johnson studied and reported both on healthy sexual function and sexual dysfunction for the first time. They described four phases of the human sexual response cycle, as follows: excitement, plateau, orgasm, and resolution. Nowadays, the accepted classification of FSD consists of disturbances in desire, including hypoactive sexual desire disorders (HSDD), sexual aversion disorders, sexual arousal disorders, orgasmic disorders, and sexual pain disorders, including dyspareunia and vaginismus (3, 6-9). FSD can further be classified as primary or secondary and persistent or situational (10).
Sexuality is a complex human behavior that affects many aspects of life. Intimate sexual function is one of the best predictors of quality of life, and sexual dysfunction causes many problems for couples. Some researchers have found that the frequency of sexual relationship and sexual satisfaction are positively associated with marital satisfaction $(11,12)$. Among other factors, illicit drug dependency changes sexual function. For instance, cannabis increases sexual emotion, sexual function, and sexual pleasure. Moreover, opioids act on a variety of neurotransmitters in the brain, including endorphins. Furthermore, morphine has been found to inhibit sexual behavior in a dose-dependent manner through a complex pharmacological domain $(13,14)$.

\section{Objectives}

A significant number of men who misuse opioids have

Copyright (C) 2016, Zahedan University of Medical Sciences. This is an open-access article distributed under the terms of the Creative Commons Attribution-NonCommercial 4.0 International License (http://creativecommons.org/licenses/by-nc/4.0/) which permits copy and redistribute the material just in noncommercial usages, provided the original work is properly cited. 
Anvar Abnavi M et al.

sexual problems. Until now, most studies on drug abuse and sexual performance have focused on addicted populations, and have usually considered men. Although many studies have looked at the frequency of sexual dysfunction in women, limited research has focused on the impact of addiction on spouse sexual function. To the best of our knowledge, few studies have been conducted on the effect of males' opium dependency on their wives' sexuality. Thus, the present cross-sectional study aimed to assess the prevalence of FSD among women with addicted partners. We hypothesized that substance dependency in males would affect their wives' sexual function.

\section{Patients and Methods}

This cross-sectional controlled study was conducted on 340 women of reproductive age ( 25 - 50 years old) selected through convenience sampling. The participants were assigned to two groups. The case group included 160 women whose husbands were opioid dependent. Some of them were the wives of opioid-dependent males hospitalized in the addiction treatment units of teaching hospitals affiliated with the Shiraz University of Medical Sciences, Shiraz, Iran. Other women were encountered in centers where opioid-dependent males' spouses were referred for group therapies. In contrast, the control group $(n=160)$ included women whose spouses were not opioid dependent; they were selected from the general population referring to the clinics of the Shiraz University of Medical Sciences. After giving informed consent, the participants were interviewed privately according to the DSM-IV-TR criteria by a senior female medical student who was one of the researchers and had been properly trained regarding the nature of the study. The interview focused on HSDD, sexual arousal disorder, orgasmic disorder, and sexual pain disorder. In addition, the subjects' demographic information, such as age, level of education, marital status, and duration of marriage, was obtained using a self-constructed questionnaire designed by the authors. To include the women in the study, we required a minimum of 6 months of opioid dependency in their husbands. The exclusion criteria of the study were a history of substance use disorders, gynecological disorders (GYN), and chronic medical disease that has been shown to affect sexual functioning (e.g. hypertension, diabetes mellitus, chronic kidney disease, cancer, spinal cord injury, lupus, fibromyalgia, chronic pain and chronic depression). It should be noted that the questionnaires were anonymous and participation in the study was voluntary.

The study data were analyzed using the SPSS statistical software (version 15). The chi-square test was used for categorical data, while the t-test was utilized for continuous data. In addition, $\mathrm{P}<0.005$ was considered as statistically significant. The protocol for this study was approved by the ethics committee of the Shiraz University of Medical Sciences, Shiraz, Iran.

\section{Results}

Out of the 340 women who were selected, 5 in the case group and 15 in the control group were excluded due to missing data. Ultimately, 320 females of reproductive age were included into the study. The mean ages of the case and the control group were 36.35 and 33.2 years, respectively. In this study, statistical significance was defined as $\mathrm{P}<0.05$. Table 1 shows the participants' demographic information. It should be noted that in terms of demographic characteristics, there was no significant difference between the case and the control group ( $P>0.05)$, so, we could use further statistical methods on the data.

Table 2 shows the frequency of sexual dysfunction in the two study groups. According to the results, approximately more than $50 \%$ of the participants had problems in at least one domain of sexual function. Moreover, the main FSD observed in the case women was HSDD (75.46.9\%) followed by sexual aversion disorder (73.46.2\%), sexual arousal disorder (65.40.9\%), orgasmic disorder (59.37.1\%), and sexual pain disorder (45.28.5\%). Furthermore, 75 out of the 155 women in the case group (46.9\%) and 16 out of the 145 women in the control group (10\%) had HSDD, and the difference between the two groups was statistically significant $(\mathrm{P}<0.05)$. In addition, 73 women in the case group (46.2\%) and 20 in the control group (12.6\%) had sexual aversion disorder, with a significant difference between the two groups $(\mathrm{P}<0.05)$. In this study, HSDD was the most prevalent sexual disorder among the study participants.

\begin{tabular}{|c|c|c|}
\hline & Case & Control \\
\hline \multicolumn{3}{|l|}{ Age range } \\
\hline $15-29$ & $43(26.9)$ & $61(38)$ \\
\hline $30-39$ & $72(45)$ & $51(31.9)$ \\
\hline $40-50$ & $45(28.1)$ & $48(30)$ \\
\hline \multicolumn{3}{|c|}{ Duration of marriage, $y$} \\
\hline $1-10$ & $68(43)$ & $79(49.4)$ \\
\hline $11-20$ & $57(36.1)$ & $50(31.3)$ \\
\hline$>20$ & $33(20.9)$ & $31(19.4)$ \\
\hline \multicolumn{3}{|c|}{ Level of education } \\
\hline Elementary & $94(62.3)$ & $58(36.5)$ \\
\hline Diploma & $48(31.8)$ & $84(52.8)$ \\
\hline University & $9(6)$ & $17(10.7)$ \\
\hline
\end{tabular}

${ }^{a}$ Values are presented as No. (\%). 
Table 2. The Frequency and Percent of Sexual Disorders in the Case and the Control Group (Categories Marked by Stars Show Statistical Significance $)^{\mathrm{a}}$

\begin{tabular}{lcc}
\hline Sexual Disorder & Case & Control \\
\hline HSDD & & \\
\hline Yes & $75(46.9)$ & $16(10)^{\mathrm{b}}$ \\
\hline No & $85(53.1)$ & $144(90)^{\mathrm{b}}$ \\
\hline Sexual aversion disorder & & \\
\hline Yes & $73(46.2)$ & $20(12.6)^{\mathrm{b}}$ \\
\hline No & $87(53.8)$ & $140(87.5)^{\mathrm{b}}$ \\
\hline Sexual arousal disorder & & \\
\hline Yes & $65(40.9)$ & $74(38.9)$ \\
\hline No & $75(49.7)$ & $83(52.9)$ \\
\hline Orgasmic disorder & & \\
\hline Yes & $59(37.1)$ & $43(27)$ \\
\hline No & $100(62.9)$ & $116(72.9)$ \\
\hline Sexual pain disorder & & \\
\hline Yes & $45(28.5)$ & $47(29.4)$ \\
\hline No & $113(71.5)$ & $113(70.7)$ \\
\hline $\mathrm{a}$ Values are presented as frequency $(\%)$. & \\
\hline $\mathrm{b}<0.05$. & & \\
\hline
\end{tabular}

\section{Discussion}

The findings of our study showed the importance of FSD. This disorder was a significant problem affecting a considerable number of women in both the case and control groups (Table 2). This high prevalence may have resulted from various causes.

Although studies have shown that many factors, such as age and level of education, affect sexual function (15-17), the findings of the current study revealed no relationship between the demographic characteristics, that is, age, duration of marriage, and level of education, and sexual dysfunction.

As can be seen in Table 2, the frequency of HSDD and aversive sexual desire disorder was more common in the case group than the control group, and the difference was statistically significant $(\mathrm{P}<0.05)$. The high frequency of HSDD among the addicts' spouses exhibited in this study was in line with the study performed by Noori et al. that showed a high prevalence of HSDD in addicts' spouses (18). However, Noori et al. included no control groups in their study, and consequently, it was not possible to compare the characteristics of the subjects with those of women whose husbands were not addicted. The findings of the present study showed that the addicts' spouses suffered from HSDD significantly more than the control group. Another finding was the higher frequency of orgasmic disorder in the case group; however, this difference was not statistically significant. The higher rate of orgasmic disorder among the addicts' spouses obtained in this research was in line with the study by Noori et al. In contrast to our research, in one study conducted on 2626 women in Iran in 2006, 31.5\% of the subjects (759) suffered from sexual disorder, and the most prevalent disorder was orgasmic disorder, followed by desire disor$\operatorname{der}(19)$.

In the DSM-IV-TR, sexual desire disorders are divided into two classes, as follows: 1) HSDD characterized by a deficiency or lack of sexual fantasies and desire for sexual activity and 2) sexual aversion disorder characterized by an aversion to and avoidance of genital contact with a sexual partner. The literature confirms the high prevalence of HSDD compared to the other conditions. No single cause of HSDD has been defined; however, physiological, psychological, and sociocultural factors that contribute to female sexual desire may all be important in its development $(20,21)$. Master and Johnson's linear model of sexual response does not always work for females. Some factors, such as emotional intimacy and relationship satisfaction, may change this model. Studies have shown that the motivating factors for female sexual desire are very complicated. Sexual desire and the presence or absence of orgasm could result from multiple cultural and environmental factors, as well as from interpersonal and intrapersonal distresses, and are greatly affected by emotional intimacy (2). Since addiction in the family could be the origin of many stressors and disputes, such stresses and interpersonal turmoil could have a decisive role in decreasing females' sexual desire toward their addicted husbands.

Researchers have found that sexual response phases in women are a combination of mental and physical responses which overlap with one another $(2,3)$. In general, women have diverse reasons to initiate or agree to have sex with their partners. Sexual motivation in females is far more complicated than just the presence or absence of sexual desire and is characterized by thinking or fantasizing about sex and longing to have sex. Moreover, the decision to be sexual may originate from a conscious wish for emotional closeness or result from seduction or a suggestion from a partner. Addicted couples often have conflicts over money and drugs; so that love gradually flies out of the window, and most often these couples' relationships end at a sad, bitter point $(11,22,23)$. Hence, this kind of relationship is expected to have a negative impact on sexuality.

Sexual desire disorder was the most prevalent FSD in our study. This study estimated the prevalence of sexual disorders among the spouses of addicted men. of course, further studies are needed in order for better characterization and understanding of FSD epidemiology.

One of the limitations of this study was the difficulty of gaining access to the case group sample and persuading them to cooperate with the researchers. In addition, when they agreed to take part in the study, the interviewer had to meet them out of their group. Moreover, the subjects might have answered the questions conservatively due to 
the particular nature of the study subject, that is, sexual behavior, in Iranian culture. Another limitation of the study was a lack of control of other contributing factors, such as the economic status of the family and sexual disorders and duration of opioid dependency in addicted husbands, which are assumed to have an effect on their wives' sexual dysfunctions. Thus, these factors are recommended for consideration in future research.

\section{Acknowledgments}

We appreciate the work of the research improvement center of Shiraz University of Medical Sciences, Shiraz, Iran and Ms. A. Keivanshekouh in improving the use of English in the manuscript. It must be noted that this article is relevant to Dr. Sara Ghaffarpour's thesis and was approved by Shiraz University of Medical Sciences with grant number 2814 .

\section{Footnotes}

Authors' Contribution:Study concept and design: Anvar and Ahmadi; acquisition of data: Hamidian and Sara Ghaffarpour; analysis and interpretation of data: Anvar and Sara Ghaffarpour; drafting of the manuscript: Hamidian and Anvar; critical revision of the manuscript for important intellectual content: Hamidian and Anvar; statistical analysis: Anvar; administrative, technical, and material support: Hamidian, Anvar, and Ahmadi; study supervision: Anvar and Ahmadi.

Funding/Support:The present study was financially supported by the Shiraz University of Medical Sciences with grant number 2814 .

\section{References}

1. Fourcroy JL. Regulatory issues in female sexual dysfunction. Int Impot Res. 2007;19(5):526-9. doi: 10.1038/sj.ijir.3901595. [PubMed: 17786156]

2. Frank E, Anderson C, Rubinstein D. Frequency of sexual dysfunction in "normal" couples. N Engl J Med. 1978;299(3):111-5. doi: 10.1056/NEJM197807202990302. [PubMed: 661870]

3. Pauls RN, Kleeman SD, Karram MM. Female sexual dysfunction: principles of diagnosis and therapy. Obstet Gynecol Surv. 2005;60(3):196-205. [PubMed:16570398]

4. Morley JE, Kaiser FE. Female sexuality. Med Clin North Am 2003;87(5):1077-90. [PubMed:14621332]

5. Berman JR. Physiology of female sexual function and dysfunction. Int J Impot Res. 2005;17 Suppl 1:S44-51. doi: 10.1038 sj.ijir.3901428. [PubMed:16391543]

6. Leiblum SR. Definition and classification of female sexual disor- ders. Int JImpot Res. 1998;10 Suppl 2:S104-6. [PubMed: 9647970]

7. Masters WH, Johnson VE. Human sexual response. Boston: Little, Brown \& Co; 1966

8. Kammerer-Doak D, Rogers RG. Female sexual function and dysfunction. Obstet Gynecol Clin North Am. 2008;35(2):169-83. doi: 10.1016/j.ogc.2008.03.006. [PubMed:18486835]

9. Marthol $\mathrm{H}$, Hilz MJ. [Female sexual dysfunction: a systematic overview of classification, pathophysiology, diagnosis and treatment]. Fortschr Neurol Psychiatr. 2004;72(3):121-35. doi: 10.1055/s2004-818357. [PubMed:14999592]

10. Plouffe L. Screening for sexual problems through a simple questionnaire. Am J Obstet Gynecol.1985;151(2):166-9. [PubMed: 4038584]

11. Zakhari R. Female sexual dysfunction: a primary care perspective. J Am Acad Nurse Pract. 2009;21(9):498-505. doi: 10.1111/j.17457599.2009.00440.x. [PubMed: 19845807]

12. Meltzer AL, McNulty JK. Body image and marital satisfaction: evidence for the mediating role of sexual frequency and sexual satisfaction. J Fam Psychol. 2010;24(2):156-64. doi:10.1037/a0019063. [PubMed: 20438191]

13. Chekuri V, Gerber D, Brodie A, Krishnadas R. Premature ejaculation and other sexual dysfunctions in opiate dependent men receiving methadone substitution treatment. Addict Behav. 2012;37(1):124-6. doi: 10.1016/j.addbeh.2011.08.005. [PubMed: 21920671]

14. Agmo A, Paredes RG, Contreras JL. Opioids and sexual behavior in the male rabbit: the role of central and peripheral opioid receptors. J Neural Transm Gen Sect.1994;97(3):211-23. [PubMed: 7873130

15. Degauquier C, Absil AS, Psalti I, Meuris S, Jurysta F. [Impact of aging on sexuality]. Rev Med Brux. 2012;33(3):153-63. [PubMed: 22891587]

16. Pakpour AH, Yekaninejad MS, Zeidi IM, Burri A. Prevalence and risk factors of the female sexual dysfunction in a sample of infertile Iranian women. Arch Gynecol Obstet. 2012;286(6):1589-96. doi: 10.1007/s00404-012-2489-x. [PubMed: 22850887]

17. Hayes RD, Dennerstein L, Bennett CM, Sidat M, Gurrin LC, Fairley CK. Risk factors for female sexual dysfunction in the general population: exploring factors associated with low sexual function and sexual distress. J Sex Med. 2008;5(7):1681-93. doi:10.1111/j.17436109.2008.00838.x. [PubMed:18410300]

18. Noori RHR, Solaimani-nia L, Narenjiha H, Assari S, Moghani Lankarani M. Impact of spouse's opiate dependence on the partner's sexual function. J Fam Reproudactive Health. 2008;2(2):185-90.

19. Safarinejad MR. Female sexual dysfunction in a populationbased study in Iran: prevalence and associated risk factors. Int J Impot Res. 2006;18(4):382-95. doi: 10.1038/sj.ijir.3901440. [PubMed: 16395324]

20. Davison SL. Hypoactive sexual desire disorder. Curr Opin Obstet Gynecol. 2012;24(4):215-20. doi: 10.1097/GCO.0b013e328355847e. [PubMed: 22729093]

21. Aisuodionoe-Shadrach OI. Perceptions of female sexual health and sexual dysfunction in a cohort of urban professional women in Abuja, Nigeria. Niger J Clin Pract. 2012;15(1):80-3. doi: 10.4103/1119-3077.94104. [PubMed: 22437096]

22. Rosenbaum M. When drugs come into the picture, love flies out the window: women addicts' love relationships. Int J Addict. 1981;16(7):1197-206. [PubMed: 7327782]

23. Simmons J, Singer M. I love you ... and heroin: care and collusion among drug-using couples. Subst Abuse Treat, Prev, Policy. 2006;1(1):1-13. doi:10.1186/1747-597x-1-7. 